\title{
Extension and Modification of Kanai's DNA Isolation Method for a Spectrum of Human Specimens Collected by Invasive and Noninvasive Methods Suitable for Genotyping Studies
}

\author{
K.N. ArulJothi, Irusappan Sivaraj, Suruthi Abirami B, \\ M.K. Harishankar and Devi Arikketh* \\ Department of Genetic Engineering, SRM University, Chennai - 603203, India. \\ http://dx.doi.org/10.13005/bbra/2135
}

(Received: 17 February 2016; accepted: 10 April 2016)

\begin{abstract}
There are a number of conventional methods and kits available for human genomic DNA isolation. These methods however come with limitations such as high cost, time-consuming, hazardous, and complex steps. We propose an extended and modified kanai's method that can be used for DNA isolation from various human specimens (blood, clot, saliva, urine, and cell lines) and from Gram-negative bacterial samples. The DNA isolated by this method was tested for suitability in genetic analysis techniques such as PCR RFLP, ARMS PCR, and High Resolution Melt analysis. The DNA isolated had high purity (mean $A_{260} / A_{280}=1.7$ to 1.8 ) and was stable at $4^{\circ} \mathrm{C}$ and $-20^{\circ} \mathrm{C}$. This method is suitable for very low volume of blood $(20 \mu \mathrm{l})$, long stored blood (3 years), and also for noninvasive samples. The DNA gave consistent and accurate results in PCR RFLP, ARMS, and HRM techniques. We have demonstrated that the DNA isolation method is an effective method for fresh blood, blood clot, saliva, urine and cell line samples and we prove its applicability in genotyping studies.
\end{abstract}

Key words: High Resolution melt analysis, Genetic analysis, ARMS PCR, blood clot.

Recently, molecular analysis of genomic DNA has become indispensable in genetic diagnostics and forensic analysis. The major sources of genomic DNA include fresh blood, clotted blood, lymphocytes, saliva, and exfoliated cells. ${ }^{1,2}$ Of these sample sources, blood and saliva are highly reliable and are most commonly used for genetic studies. ${ }^{3,4,5,6}$

Each type of sample requires a specific protocol to isolate genomic DNA. At present, there are numerous commercial kits available $e^{7,8,9,10}$ that are specific to each type of specimen, which leads to a multiplicity of kits in the laboratory for DNA

\footnotetext{
* To whom all correspondence should be addressed. Mob.: +91-9444907563, 044-27417817;

E-mail: adevipradeep@gmail.com
}

isolation purposes. The cost of commercial kits and the multiplicity of kits is a limiting factor ${ }^{11,12}$ for research in laboratories in certain developing and underdeveloped nations. This work provides a single DNA isolation protocol that can be applied to a wide range of specimens; it is efficient, expeditious, and cost-effective in molecular diagnosis and research. The same solutions and protocol can be used to isolate DNA from different human samples such as urine, saliva, buccal swab, and cell lines.

PCR RFLP is a widely used genotyping method today. The SNP analyses of human samples play an important role in disease diagnosis ${ }^{13}$ pharmacokinetics ${ }^{14,15}$ and many other fields. The polymerase chain reaction needs high purity DNA, and it will fail if undesirable chemicals are present. 
Hence, PCR RFLP ${ }^{16}$ genotyping was chosen to ensure the high quality of DNA acceptable for molecular analysis. ARMS ${ }^{17}$, another method of genotyping that uses allele-specific primers for polymerase chain reaction, also needs good quality, contaminant-free DNA samples. High Resolution Melt ${ }^{18,19}$ is a real-time gene variant analysis method that works on the principle that when a saturated dye is dissociated from a double-stranded DNA the decrease in the intensity of the signal is recorded and the minor difference due to a base pair change is compared with a reference fragment of known sequence.

The main objective in the development of this two-step DNA isolation method is to (i) avoid repeated blood sample collection from patients, (ii) use unwanted blood clot sample as a source for genetic analysis, (ii) use noninvasive samples for genetic analysis, (iv) use long stored blood samples for genetic analysis, (v) reduce the time and cost for DNA isolation per sample, and (vi) reduce the use of multiple methods/kits in laboratories.

A wide range of human specimens that include fresh blood, stored blood, clotted blood, lymphocytes, cell lines, saliva, and urine were considered for genomic DNA isolation in this twostep DNA isolation method. The isolated DNA was tested for suitability in PCR-based genetic analytical studies as PCR RFLP, ARMS, and High Resolution Melt (HRM) analysis. As the proposed method covers a wide range of sample types and yields high quality DNA, it proves advantageous over existing commercial and conventional methods.

\section{MATERIALSAND METHODS}

\section{Reagents}

Cell lysis buffer is prepared with 150mmole/L NaCl, 2\% SDS, 50mmole/L EDTA, proteinase K (50ng/ $\mu \mathrm{l}$ ) (Himedia) chloroform, and ethanol (sigma).

\section{Human specimen}

Human specimens like fresh blood, fresh blood clot, stored blood sample, saliva sample, urine, lymphocytes, and cell lines were used to isolate DNA. Human blood, saliva, and urine samples were obtained from volunteers after obtaining written consent. The study was approved by Institutional Ethical committee, SRM Medical College Hospital and Research Centre, SRM University, Chennai

\section{Sample collection and processing}

In our work, each human specimen was processed in the following ways.

\section{Blood clot}

After removing excess serum from the collection vials, blood clots were weighed and approximately $0.1-0.2$ grams of clot was taken and mechanically disrupted using micro tips until it turned into a semi-liquid state; separate tips can be used for different samples to avoid cross contamination.

\section{Blood sample}

$200 \mu \mathrm{l}$ of fresh/stored blood was taken and lysis buffer added, followed by the DNA isolation procedure.

\section{Finger prick method}

10 to $30 \mu$ l of blood was collected using a pipette from the finger prick and double the volume of lysis buffer was added; then the DNA isolation procedure was followed.

\section{Urine sample}

$50 \mathrm{~mL}$ of first-morning urine was collected and centrifuged at 10,000 rpm for $15 \mathrm{mi}$ at room temperature. The pellet obtained was washed with 1x PBS and again centrifuged at $5000 \mathrm{rpm}$ for $5 \mathrm{~min}$ at room temperature. The resulting pellet was dissolved in 100 $\mu$ l of 1X PBS buffer and this cell suspension was taken in a microfuge tube for DNA isolation.

\section{Saliva sample}

Saliva samples (approximately $500 \mu \mathrm{l}$ ) can be collected directly in microfuge tubes and the proposed procedure can be followed. To validate whether the method is applicable for stored saliva samples, the saliva samples were stored at room temperature for 4 days and DNA isolation was performed everyday up to 4 days.

\section{Cell lines}

Adherent cells were trypsinized using $0.5 \%$ trypsin and detached from the culture vessel. The suspension was centrifuged at $5000 \mathrm{rpm}$ for 5 min to remove medium and trypsin. To the obtained cell pellet the lysis buffer was added directly. The cell lines U87 (glioblastoma) and A431 (skin carcinoma) used in this work were purchased from NCCS Pune, India. 


\section{Lymphocyte}

Fresh blood was taken and lymphocytes were isolated using the ficoll-hypaque method. ${ }^{20}$ 200 to $300 \mu$ l of buffy coat retrieved from this method can be directly used for DNA isolation.

\section{Gram-Negative Bacteria}

Sporosarcina pasteurii SRMNP1 (accession number- KF214757), E.coli Top10 (MTCC, Chandigarh, India) were used for analysis. $1.5 \mathrm{~mL}$ of overnight culture was taken and centrifuged at $8000 \mathrm{rpm}$ for $10 \mathrm{~min}$. The supernatant was discarded and the pellet obtained was considered for bacterial genomic DNA isolation by the same procedure as for human specimen.

DNA isolation procedure

\section{Cell lysis}

Appropriate human specimen (fluid sample $\leq 200 \mu \mathrm{l}$ or clot $-200 \mathrm{mg}$, for bacteria $1 \mathrm{~mL}$ overnight culture taken and pelleted) was taken in a microfuge tube and $400 \mu$ l of lysis buffer was added to it (in finger prick method, for10 $\mu$ l blood sample $20 \mu$ of lysis buffer was added), then $2 \mathrm{uL}$ (50ng/ $\mu \mathrm{l}$ ) of proteinase $\mathrm{K}$ was added, and the tube was incubated at 55-60p C for $1 \mathrm{~h}$. After incubation $1 \mu \mathrm{l}$ of proteinase $\mathrm{K}$ was added to the tube and mixed well. The tubes were incubated for $5 \mathrm{~min}$ at 55p C. Then $150 \mu \mathrm{l}$ of $6 \mathrm{M} \mathrm{NaCl}$ and $600 \mu \mathrm{l}$ of chloroform were added to it. The tubes were mixed gently by inverting them and then centrifuged at $5000 \mathrm{rpm}$ for $5 \mathrm{~min}$ at room temperature.

\section{DNA recovery}

The aqueous phase was recovered and added to a fresh tube containing $800 \mathrm{uL}$ of $90 \%$ ethanol. The tube was then centrifuged at 5000 rpm for 5 min at room temperature. The supernatant was discarded and to the pellet $70 \%$ ethanol was added and centrifuged at 10,000 rpm for $5 \mathrm{~min}$ at RT. The pellet obtained was air dried and dissolved with TE buffer. For better stability the samples can be stored at -20p C. The obtained genomic DNA was visualized using $0.8 \%$ agarose gel. The DNA was quantified using Nanodrop lite spectrophotometer (Thermo scientific)

\section{Stability and Integrity}

The DNA samples isolated by this method were tested for integrity and stability under various storage conditions. The samples were stored at room temperature $\left(30^{\circ} \mathrm{C}\right.$ approximately), $4^{\circ} \mathrm{C}$, and $20^{\circ} \mathrm{C}$ for a period of 1 month and the quality of DNA was analyzed through agarose gel electrophoresis.

\section{PCR RFLP Genotyping}

The PCR for exon 8 of SCARB1 gene was done for the DNA samples isolated by this method with thermal cycles of $95^{\circ} \mathrm{C}-30 \mathrm{~s}, 71.5^{\circ} \mathrm{C}-30 \mathrm{~s}$, and $72^{\circ} \mathrm{C}-30 \mathrm{~s}$ for 35 cycles using forward primer 5'CCTTGTTTCTCTCCCATCCTCACTTCCTCGACGCЗ' and reverse primer 5'CACCACCCCAG CCCACAGCAGC 3'. ${ }^{21}$ Restriction digestion was carried out with the reaction mix containing $10 \mu \mathrm{l}$ of PCR product, $0.1 \mu \mathrm{l}$ of Hin1I (10U/ $\mu \mathrm{l})$ (thermo scientific), $2 \mu \mathrm{l}$ of $10 \mathrm{x}$ buffer, and 7.9 $\mu \mathrm{l}$ of double distilled water.

\section{Allele-specific PCR - ARMS}

Amplification refractory mutation system - Tetra primer PCR is a one-step approach used widely for genotyping. ${ }^{22}$ The Paraoxanase gene polymorphism Q192R was considered to corroborate the applicability of the DNA isolation method. The allele-specific primers were designed using primer1 (http://primer1.soton.ac.uk/ primer1.html ${ }^{23}$ online tool, the outer forward primer -5'GGAATAGACAGTGAGGAATGCCAGTTAT, outer reverse primer - 5'ACATTTCAG AGATTCACATACTTGCCA, 'A' allele-specific primer 5' ATCACTATTTTCTTGACCCCTAC TTCCG, G' allele-specific primer 5'TAAAC CCAAATACATCTCCCAGGCTT were used for ARMS PCR. The PCR conditions for the reaction are $95^{\circ} \mathrm{C}-1 \mathrm{~min}, 60^{\circ} \mathrm{C}-1 \mathrm{~min}$ and $72^{\circ} \mathrm{C}-1 \mathrm{~min}$ for 35 cycles. This specific segment of exon 6 was amplified and visualized by running in agarose gel electrophoresis for genotyping purpose.

\section{High resolution melt - Mutation screening}

High resolution melt analysis is an advanced technique used for genotyping and to screen the recurrent and novel mutations in genomic DNA. LDLR gene exon 10 was considered for elucidating the applicability of gDNA in HRM. The gene-specific primers designed to suit the HRM conditions were used in the experiment. ${ }^{24}$ The forward primer 5' AGATGAGGG CTCCTGGTGCGATGCC3' and reverse primer 5' GCCCTTGGTATCCGCAACAGAGACA3' were used to amplify the 5' segment of exon 10 from three samples of known genotype (GG, GA, AA). The program for PCR is denaturation at $95^{\circ} \mathrm{C}$ for 30 s, annealing at $65^{\circ} \mathrm{C}$ for $30 \mathrm{~s}$ and extension at $72{ }^{\circ} \mathrm{C}$ for $30 \mathrm{~s}$; later the amplified product is analyzed by $\mathrm{HRM}$ by increasing the temperature from $65^{\circ} \mathrm{C}$ to 
$95^{\circ} \mathrm{C}$, where the critical temperature of HRM for the fragment is between $85^{\circ} \mathrm{C}$ and $90^{\circ} \mathrm{C}$ (Light cycler 480, Roche)

\section{RESULTS}

\section{DNA yield and quality}

In the present work we demonstrate an improvised efficient, quick, and cost-effective DNA isolation from different human specimens and from Gram-negative bacteria (E.coli Top10, Sporosarcina pasteurii SRMNP1) and its pertinence to molecular analysis and other research. The genomic DNA isolated from different samples were visualized under UV trans-illuminator and documented (Figure.1). The yield and quality of DNA are given in table.1.

DNA Stability and Integrity

The DNA samples stored at $4^{\circ} \mathrm{C}$ and $-20^{\circ} \mathrm{C}$ were stable for 1 month, whereas the DNA samples kept at room temperature started degrading (Figure.2.)

\section{PCR RFLP Genotyping}

PCR for SCARB1 gene was done for the DNA samples isolated by this method with thermal cycles at $95^{\circ} \mathrm{C}-30 \mathrm{~s}, 71.5^{\circ} \mathrm{C}-30 \mathrm{~s}$, and $72^{\circ} \mathrm{C}-30 \mathrm{~s}$ for 35 cycles; a product of 218 base pairs was obtained from samples of all sources. A base conversion of $\mathrm{C}>\mathrm{T}$ of rs5888 polymorphism was genotyped with Hin1I restriction enzyme, and the bands were visualized with $2.5 \%$ agarose gel electrophoresis (Figure 3).

\section{Allele-specific ARMS tetra primer PCR}

DNA isolated from different human specimens was tested for allele-specific primer PCR technique. The results were visualized with 2.5\% agarose gel electrophoresis (Figure 4). The DNA quality matched the applicability in allele-specific primer PCR analysis. The genotypes can be clearly differentiated by ARMS PCR using the DNA isolated by this method.

\section{High resolution melt - Mutation screening}

The DNA samples were subjected to mutation screening of exon 10 of LDLR gene using high resolution melt analysis. The increased intensity of ResoLight high-resolution melting dye with increase in time or cycle indicates the amplification of the fragment with the given sample in the reaction (Figure 5.a). High resolution melt curves are distinctive and conclusive to differentiate heterozygous genotypes (Fig 5.b and c).

\section{DISCUSSION}

The two-step DNA isolation method is a modified procedure of Kanai's DNA isolation method used for blood clot. ${ }^{25}$ This method is employed to isolate gDNA from other human specimens for the first time in our work with a few modifications. The DNA isolated by this method from various specimens yielded a high quality DNA suitable for further downstream PCR-based applications. ${ }^{26}$ In this work, apart from human specimens the method has been used to isolate

Table 1. DNA concentration and A260/A280 ratio for different human specimens and Gram negative bacteria samples

\begin{tabular}{lccc}
\hline Specimen & No.of samples & DNA conc. (ng/ $\mu \mathrm{l}) \pm \mathrm{SD}$ & $\mathrm{A}_{260} / \mathrm{A}_{280} \pm \mathrm{SD}$ \\
\hline Human Specimen & & & \\
Stored anticoagulated blood & 10 & $57 \pm 0.8$ & $1.76 \pm 0.3$ \\
Blood clot & 25 & $50 \pm 1.3$ & $1.82 \pm 0.12$ \\
Fresh anticoagulated blood & 20 & $49 \pm 4$ & $1.88 \pm 0.16$ \\
Saliva & 12 & $313 \pm 13.5$ & $1.81 \pm 0.04$ \\
Urine & 10 & $21 \pm 6.2$ & $1.4 \pm 0.11$ \\
Cell line & $2^{*}$ & $1183 \pm 20.1$ & $1.91 \pm 0.01$ \\
Lymphocyte & 10 & $460 \pm 12.4$ & $1.94 \pm 0.01$ \\
Gram-Negative bacteria & & & \\
E.coli & $3^{*}$ & $200 \pm 4.0$ & $1.7 \pm 0.3$ \\
S.pasteurii & $3^{*}$ & $200 \pm 4.0$ & $1.7 \pm 0.3$ \\
\hline
\end{tabular}

*Done in triplicateSD - Standard deviation 


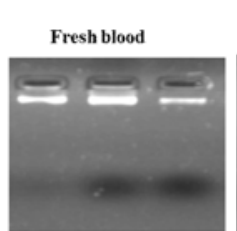

Lymphocyte

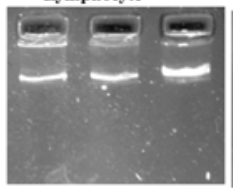

First Urine sample

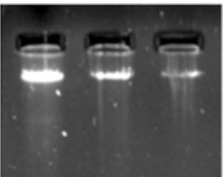

Figure 1: DNA isolation from different human specimens and negative bacteria

Sation:

Freskat elot folente
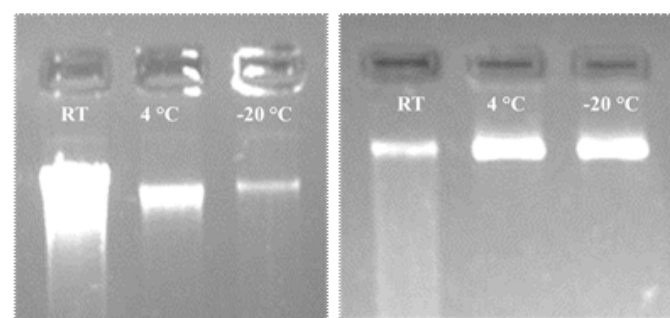

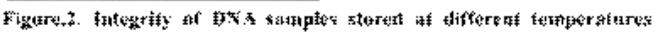
(f)

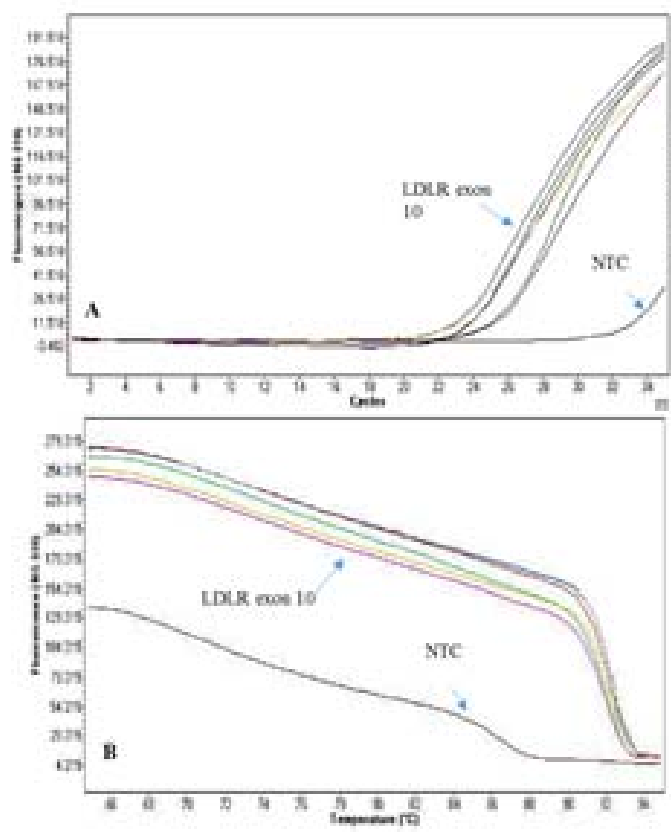

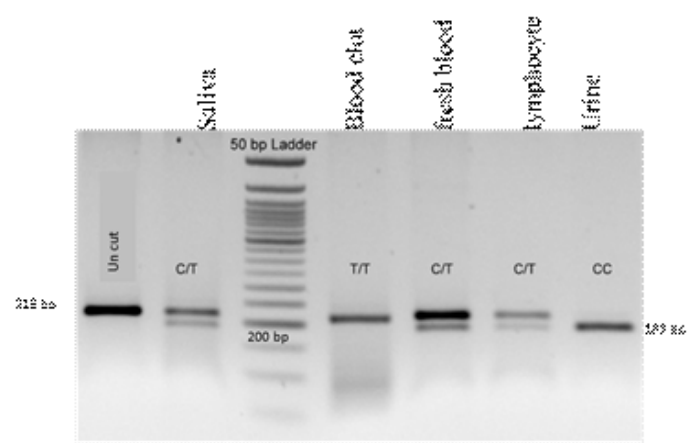

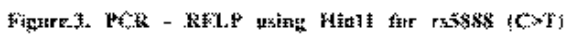

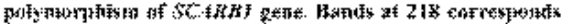

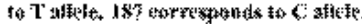
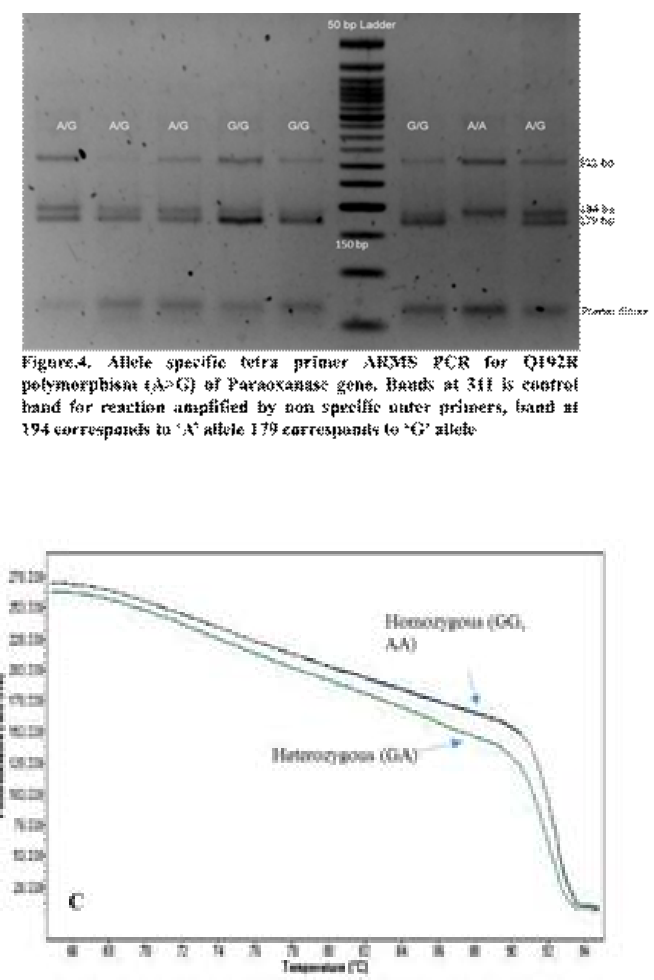

Figure.5. Amplification of LDL.R exen 10 using Rese mix (Reche) (A), HRM run for bomorygous and beteroxygoes samples in triplicates (B), HRM Shift difference between homoxygous and heteroxygous genetypes (C) 
gDNA from Gram-negative bacteria with maximum purity. ${ }^{27}$ The DNA isolated by this method was highly stable when it was stored at $4{ }^{\circ} \mathrm{C}$ and $-20^{\circ} \mathrm{C}$, whereas storing at room temperature led to gradual degradation of DNA sample. The applicability of the DNA isolated by the method has been substantiated using various methods such as PCR RFLP, ARMS PCR, and HRM techniques that are widely used in human genetic analysis. ${ }^{28}$

This two-step isolation method is suitable for up to a minimum volume of $20 \mu \mathrm{l}$ and can yield good quality DNA and, hence, avoids drawing large volumes of blood from patients. The clotted blood discarded after biochemical analysis can also be used to get better quality DNA. Saliva and firstmorning urine, which are noninvasive samples, also yield good quality of DNA by this method.

Storage of blood and other samples is inevitable in molecular research. We isolated DNA in 10 different samples that had been stored at $20^{\circ} \mathrm{C}$ for 3 years. The quality and quantity of the DNA were not compromised in any respect for the long stored blood samples compared to fresh blood samples. To examine the stability and suitability of saliva sample at room temperature during transportation without ice packages, the samples were stored at RT for 4 days ; the DNA was isolated from these samples everyday till the fourth day and good quality of DNA was obtained ${ }^{29,30}$ (Figure.6). This proves that saliva samples that are transported without ice packs are also suitable for genomic DNA isolation by this method. On the other hand, only the first morning urine samples were suitable for DNA isolation by this method; urine samples collected otherwise were not consistent in yielding DNA with this method. ${ }^{31}$

Compared to the organic conventional and commercial kit methods, the two-step method

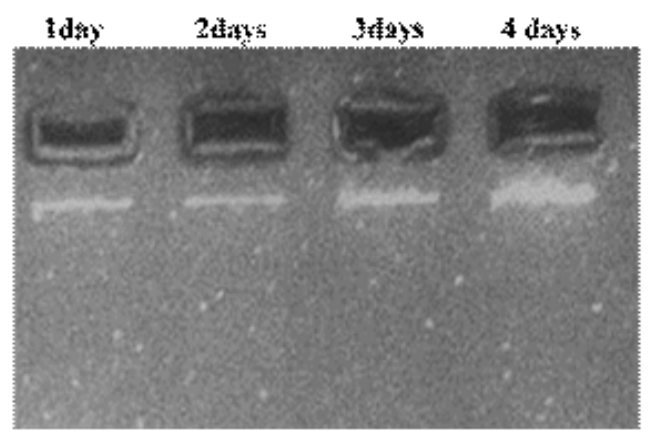

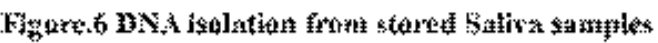

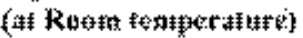

of DNA isolation is efficient and cost-effective. The method involves non-hazardous chemicals and is simple, safe, and easy to follow. Also, the DNA isolated by this method was stable and had good integrity which makes this an ideal method for DNA isolation. There are various methods and kits available for DNA isolation ${ }^{32}$ that are restricted to specific tissue or sample, whereas our proposed method can be used for a wide range of specimens and also eliminates multiplicity of kits/methods of DNA isolation in the laboratory.

\section{CONCLUSION}

The proposed method is suitable for a wide spectrum of human specimens and also for Gram-negative bacteria samples. It is suitable for cell lines, lymphocytes, fresh blood, clotted blood, low volume blood samples ( $20 \mu \mathrm{l})$, long time stored (3 years at $-20^{\circ} \mathrm{C}$ ), short time stored (up to 4 days at RT), invasive type (blood), and noninvasive type (saliva and urine) samples. It is a cost-effective and efficient method compared to existing conventional and commercial methods. The DNA isolated by this method is suitable for further PCRbased mutation analysis research.

\section{REFERENCES}

1. Ghatak S, Muthukumaran B, Nachimuthu K. A simple method of genomic DNA extraction from human samples for PCR-RFLP analysis. Journal of Biomolecular Techniques 2013; 24:224-231.

2. Wong S, Kuei J, Prasad N, Agonafer E, Mendoza A, Pemberton J et al. A simple method for DNA isolation from clotted blood extricated rapidly from serum separator tubes. Clinical Chemistry 2007; 53:522-524.

3. Sun F, Reichenberger J. Saliva as a source of genomic DNA for genetic studies: review of current methods and applications. OHDM 2014; 13(2):217-222.

4. Hansen T, Simonsen M, Nielsen F, Hundrup Y. collection of blood saliva and buccal cell samples in a pilot study on the danish nurse cohort comparison of the response rate and quality of genomic DNA. Cancer Epidemiol Biomarkers Prev 2007; 16:2072-2076.

5. Boom R, Sol A, Salimans M, Jansen L, Dillen P, Noordaa J. Rapid and simple method for purification of nucleic acids. Journal of Clinical Microbiology 1990; 28: 495-500. 
6. Koppikar P, Mulherkar R. A simple method for extraction of high molecular weight genomic DNA from buccal cells in mouthwash. Indian Journal of Biotechnology 2006; 5:477-481.

7. Lundblom K, Macharia A, Lebbad M, Mohammed A, Farnert A. High-speed shaking of frozen blood clots for extraction of human and malaria parasite DNA. Malaria 2011; 10:229.

8. Gupta R, Earley K, Sharma S. Use of human peripheral blood lymphocytes to measure DNA binding capacity of chemical carcinogens. Proc. Nati. Acad. Sci. USA 1988; 85:3513-3517.

9. Pinto G, Poloni T, Carneiro L, Baethgen F, Barth L, Pasqualotto A. Evaluation of different urine protocols and DNA extraction methods for quantitative detection of BK viruria in kidney transplant patients. Journal of virological methods 2013; 188: 94-96.

10. Psifidi A, Dovas I, Bramis G, Lazou T, Russel L, Arsenos G et al. comparison of eleven methods for genomic DNA extraction suitable for large scale whole genome genotyping and long term DNA banking using blood samples. PLOS ONE 2015; 10:1-18

11. Bali E, Diman A, Bernard A, Roosens H, Keersmaecker J. Comparative study of seven commercial kits for human DNA extraction from urine samples suitable for DNA biomarker-based public health studies. Journal of biomolecular techniques 2014; 25: 96-110.

12. Silva L, Medeiros Z, Soares C, Silva D, Filho D, Melo F. A comparison of four DNA extraction protocols for the analysis of urine from patients with visceral leishmaniasis. Revista da sociedade brasileira de medicina tropical 2014; 47(2):193197.

13. Huijsmans R, Damen J, Linden H, Hermans M. Single nucleotide polymorphism profiling assay to confirm the identity of human tissues. Journal of molecular diagnostics 2007; 9(2):205-213.

14. Berno G, Zaccarelli M, Gori C, Tempestilli M, Antinori A, Perno C et al. Analysis of singlenucleotide polymorphisms (SNPs) in human CYP3A4 and CYP3A5 genes: potential implications for the metabolism of HIV drugs. BMC Medical Genetics 2014; 15:76.

15. Hodel E, Csajka C, Ariey F, Guidi M, Kabanywanyi A, Duong S et al. effect of single nucleotide polymorphisms in cytochrome p450 isoenzyme and $\mathrm{N}$-acetyltransferase 2 genes on the metabolism of artemisinin-based combination therapies in malaria patients from cambodia and tanzania. Antimicrobial agents and chemotherapy 2013; 57(2):950-958.

16. Yasuo Fukumori, Shiro Ohnoki, Hirotoshi
Shibata, Hideo Yamaguchi, Hiroaki Nishimukai Genotyping of ABO blood groups by PCR and RFLP analysis of 5 nucleotide positions, International Journal of Legal Medicine 1995; 107(4):179-182.

17. Collins A, Ke X. Primer1 Primer Design Web Service for Tetra-Primer ARMS-PCR. The Open Bioinformatics Journal 2012; 6:55-58.

18. Wittwer CT, Reed GH, Gundry CN, Vandersteen JG, Pryor RJ. High-resolution genotyping by amplicon melting analysis using LCGreen. Clin. Chem. 2003; 49(6):853-860.

19. Wittwer G. Sensitivity and specificity of single nucleotide polymorphism scanning by high resolution melting analysis. Clinical Chemistry 2004; 50(10):1748-1754.

20. Denis English, Burton R. Andersen. Single-step separation of red blood cells, granulocytes and mononuclear leukocytes on discontinuous density gradients of Ficoll-Hypaque. Journal of Immunological Methods 1974; 5(3):249-252.

21. Yin R, Feng D, Miao L, Aung L, Cao X, Yan T et al. Several genetic polymorphisms interact with overweight/obesity to influence serum lipid levels. Cardiovascular diabetology 2012; 11:123.

22. Masud R. Tetra primer ARMS-PCR relates folate/homocysteine pathway genes and ACE gene polymorphism with coronary artery disease. Mol cell biochem 2011; 355:289-297.

23. Ye S, Dhillon S, Ke X, Day C. An efficient for genotyping single nucleotide polymorphisms. Nucleic acids research 2001; 29(17):88.

24. Whittall R, Scartezini M, Li1 K, Hubbart C, Reiner Z, Abraha A et al. Development of a highresolution melting method for mutation detection in familial hypercholesterolemia patients. Ann Clin Biochem 2010; 47: 44-55.

25. Kanai N, Fujii T, Saito K, Yokoyama T. Rapid and simple method for preparation of genomic DNA from easily obtainable clotted blood, $J$ Clin Pathol 1994; 47:1043-1044.

26. Suguna S, Nandal D, Kamble S, Bharatha A, Kunkulol R. Genomic DNA isolation from human whole blood samples by non-enzymatic salting out method. Int J pharm pharm sci 2014; 6(6): 198-199.

27. Torsvik V, Goksoyr J, Daae F. High diversity in DNA of soil bacteria. Applied and environmental microbiology 1990; 56:782-787.

28. Saste S, Ghalsasi P, Kataria R, Joshi B, Mishra B, Nimbkar C. ARMS-PCR as an alternative, cost effective method for detection of FecB genotype in sheep. Indian journal of biotechnology 2012; 11:274-279.

29. Richardson J, Narendran N, Guymer R, Vu H, Baird N. Blood storage at $4^{\circ} \mathrm{C}$-factors involved 
in DNA yield and quality. J Lab Clin Med 2006;

147(6): 290-294.

30. Daniel P, Koh D, Choo G, Vivian N, Qiuyun F.

Effect of storage conditions on the extraction of

PCR-quality genomic DNA from saliva. Clinica

Chimica acta 2004; 343:191-194.

31. Hilhorst M, Theunissen R, Rie H, Paassen P,
Tervaert J. DNA extraction from long-term stored urine. Hilhorst et al. BMC nephrology 2013; 14:238.

32. Carpi F, Pietro F, Vincenzetti S, Mignini F, Napolioni V. Human DNA Extraction Methods: Patents and Applications. Recent Patents on DNA \& Gene Sequences 2011; 5:1-7. 